\title{
Cerebrospinal Fluid Pseudocyst Complicating Ventriculoperitoneal Shunt: Report of Four Cases
}

\author{
Pradyumna Pan ${ }^{1}$ \\ ${ }^{1}$ Pediatric Surgery Unit, Ashish Hospital and Research Centre, \\ Jabalpur, Madhya Pradesh, India
}

\begin{abstract}
Address for correspondence Pradyumna Pan, MCh, Pediatric Surgery Unit, Ashish Hospital and Research Centre, Jabalpur 482001, Madhya Pradesh, India (e-mail: dr_pan@rediffmail.com).
\end{abstract}

\begin{abstract}
Keywords

- cerebrospinal fluid abdominal pseudocyst

- ventriculoperitoneal shunt complication

- management

Background Cerebrospinal fluid (CSF) abdominal pseudocyst (APC) is an uncommon complication following ventriculoperitoneal (VP) shunt.

Aim To study the clinical features and management of this entity. The authors present their experience with cases of CSF pseudocyst in children.

Materials and Methods Retrospective analysis of four cases diagnosed to have APC following VP shunt between 2005 and 2015.

Results Clinical presentation was with progressive abdominal distension, highlights of intestinal obstruction, and signs of raised intracranial pressure (ICP). Diagnosis is readily made with ultrasonography and computed tomographic (CT) scan of the abdomen. The duration between insertion of the shunt and the presentation ranged from 4.11 to 12 years. In three patients, the cyst was unilocular and of varying size. The fourth one had a multilocular cyst. In three patients, the treatment involved was surgical removal of the catheter with excision of the pseudocyst wall and placement of a new catheter intraperitoneally in a different quadrant. Ultrasound-guided aspiration of the cyst and relocation of the distal end was done in one patient.

Conclusion Initial suspicion with appropriate investigation and early treatment can avert morbidity and mortality.
\end{abstract}

\section{Introduction}

Use of the peritoneal cavity for cerebrospinal fluid (CSF) absorption in ventriculoperitoneal (VP) shunting is the most successful method for managing hydrocephalus. ${ }^{1}$ Abdominal complications incorporate peritonitis, ascites, bowel and abdominal wall perforation, and inguinal hernias in 5 to $47 \%$ cases. ${ }^{1,2}$ Formation of CSF abdominal pseudocysts (APCs) is a well-recognized but not a very common complication occurring in 1 to $4 \%$ cases. ${ }^{3}$ Pseudocyst wall is composed of fibrous tissue or an inflamed serosal surface without an epithelial lining. ${ }^{4}$

An increase in CSF protein contents may also serve as a sterile inflammatory response. Delay in the diagnosis of this complication can lead to a progressive increase in size and malfunctioning of VP shunt leading to raised intracranial pressure (ICP). The recurrence of APC may occur with the incidence in the literature varying widely from 7.1 to $62.5 \%{ }^{5}$ We share our experience with four cases of CSF abdominal pseudocysts following VP shunt operation in children.

\section{received}

March 26, 2018

accepted after revision

April 30, 2018

published online

August 10, 2018

\section{Materials and Methods}

We examined the records of four patients with CSF APC treated at our institution from 2005 to 2015. The clinical features, presence of infection, etiology of hydrocephalus, prior abdominal surgery, and the treatment performed were evaluated. Abdominal ultrasound and abdominal computed tomography (CT) scan were used to demonstrate a fluid collection, echogenicity, and septations around the catheter tip. Preoperative aspirate of CSF from the shunt and aspirate from the cyst were evaluated for signs of infection.

\section{Patient 1}

An 11-year-old girl presented with progressive abdominal distension, pain, and vomiting. She was previously operated for meningomyelocele, and VP shunt was placed at 2 months of age. At 14 months of life, the shunt was revised for distal malfunction. At present, the abdomen was moderately distended with diffuse tenderness. Ultrasound 
revealed significant dilatation of the small bowel loops and echogenic peritoneal fluid (-Fig. 1). CT showed large loculated and multiseptated abdominal cysts. On exploration, a large, thick-walled, multiseptated, pseudocyst was discovered adherent to bowel loops and omentum. The VP shunt was externalized and attached to an external ventricular drainage system. Adhesiolysis with near-total excision of pseudocyst was performed and abdominal drainage was kept. CSF Gram stain and cultures were negative. A new distal catheter was subsequently introduced into the peritoneal cavity.

\section{Patient 2}

A 16-year-old adolescent boy, a diagnosed case of tubercular meningitis with VP shunt since 14 years, with complaints of progressive abdominal distension and pain in the abdomen for 3 months. The patient was neurologically stable with no evidence of raised ICP. The abdomen was noticeably distended with diffuse tenderness. Ultrasound and CT scan showed clear peritoneal fluid cyst from xiphisternum to the pelvis pushing the bowels and liver superiorly (-Fig. 2). Laparotomy and near-total cyst excision with repositioning of the shunt tip in the right subdiaphragmatic space were done (-Fig. 3). CSF collected from the cyst and shunt was sterile.

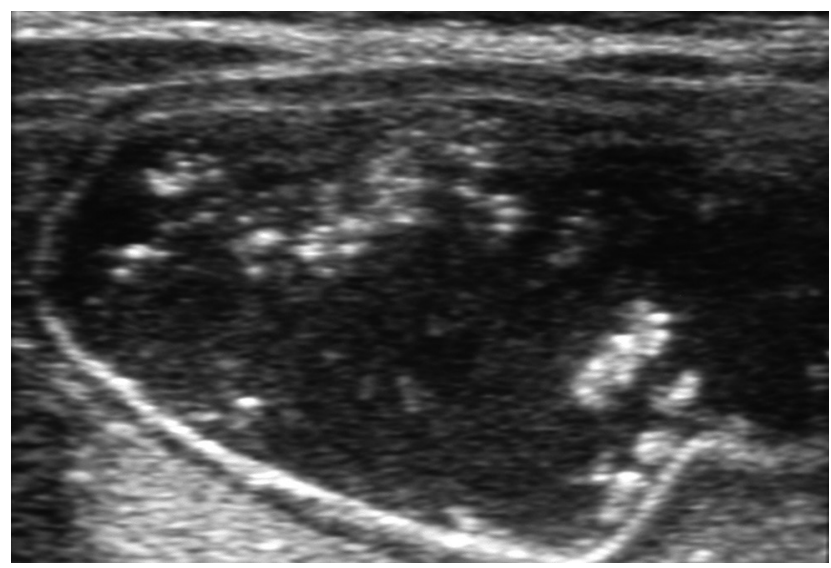

Fig. 1 USG showing echogenic peritoneal fluid collection.
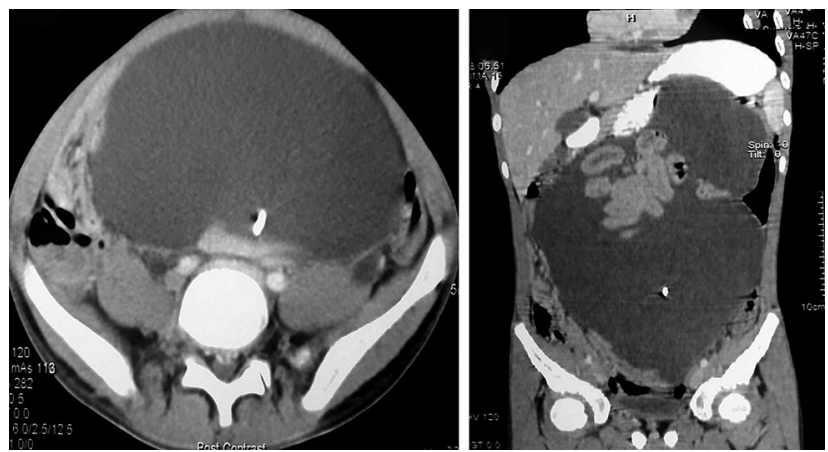

Fig. 2 CT scan showing massive pseudocyst extending from xiphisternum to pelvis with displacement of organs.
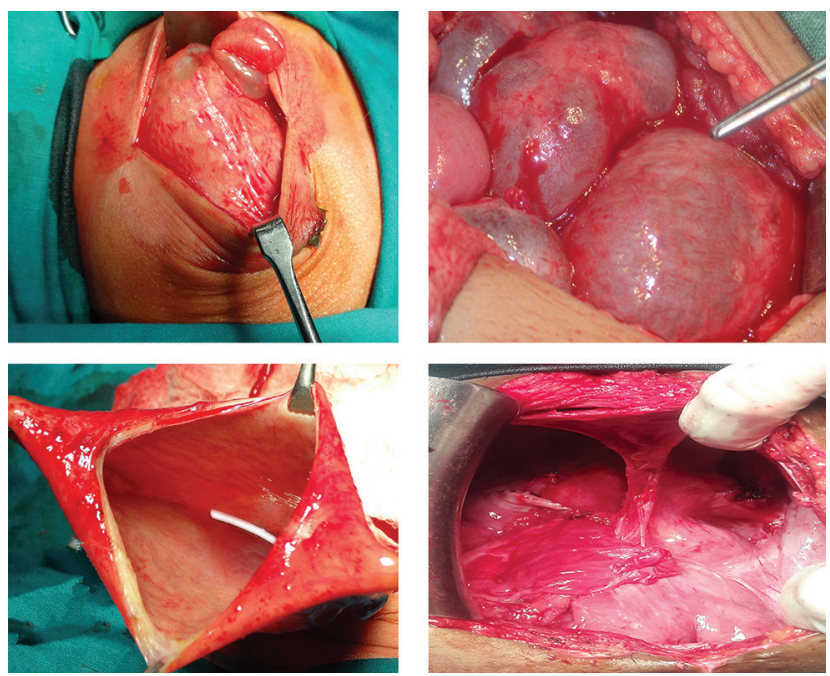

Fig. 3 Operative photo showing the pseudocyst.

\section{Patient 3}

A 5-year-old boy was diagnosed as a case of congenital hydrocephalus at 1 month of age, for which a VP shunt was inserted. He presented with abdominal lump occupying the right iliac area. Ultrasonography (USG) showed a cystic lesion $7 \times 10 \mathrm{~cm}$ in relation to the lower end of the shunt. USGguided aspiration of the cyst was done. The peritoneal end was replaced and repositioned in a different quadrant of the peritoneal cavity.

\section{Patient 4}

A 9-year-old girl underwent a VP shunt for congenital hydrocephalus at 8 months of age. Six months after the operation, she was admitted with CSF culture positive-Staphylococcus epidermis infection, and the child responded to adequate antibiotic treatment. At the age of 3.5 years, the child again presented with distal end shunt blockage, for which lower end of the shunt was revised. This time she faced with progressive abdominal distension, pain in the abdomen for 2 months, and altered sensorium. Ultrasound of the abdomen revealed gross encysted fluid with no internal septations. Cyst size was approximately $18 \times 14 \mathrm{~cm}$. CSF culture was sterile. The cyst was excised. The lower end of the shunt was changed with repositioning in the peritoneal cavity and abdominal drain was kept.

\section{Results}

The duration between insertion of the shunt and presentation ranged from 4.11 to 12 years. The etiology included congenital in two, meningomyelocele in one, and tubercular meningitis in one. The most frequent symptoms of a pseudocyst were abdominal pain and distension. Altered sensorium was seen in one. In three patients, the cyst was unilocular and of varying size. The fourth one had a multilocular cyst. The surgical management included near-total excision of the cyst with the replacement of lower end and repositioning 
of the shunt in two patients, USG-guided aspiration of the cyst with replacement and repositioning of lower end of the shunt in one patient, excision of the cyst and exteriorization of the shunt followed by replacement and repositioning of the shunt in one patient. All the patients are doing well on follow-up.

\section{Discussion}

Cerebrospinal fluid APC is an infrequent, though welldescribed, complication of VP shunt malfunction in children. The pathophysiology underlying the development of an abdominal pseudocyst is unknown. The term pseudocyst implies that the cyst is surrounded by a wall of nonepithelial tissue, such as intestinal serosa and peritoneum. The wall may have progressed from an inflammatory reaction to a focal peritonitis or low-grade infection. ${ }^{6}$ Predisposing factors for CSF pseudocyst formation include low-grade shunt infection, chronic inflammation, ${ }^{5}$ increased CSF protein content, ${ }^{7}$ peritoneal adhesion, multiple shunt revisions, and malabsorption of CSF secondary to subclinical peritonitis. ${ }^{8}$ Pseudocyst wall is composed of fibrous tissue ${ }^{9}$ or an inflamed serous surface, ${ }^{10}$ without an epithelial lining, and is filled with CSF and debris. It has been advocated that lack of an epithelial lining and the presence of inflammatory cells may hinder CSF absorption. ${ }^{11}$

Children usually present with a headache, vomiting, and drowsiness arising out of shunt malfunction. In contrast, most adults cases present with abdominal symptoms such as pain, distension, and features of intestinal obstruction, and may present with decreased appetite, constipation, fever, and lethargy.

According to Egelhoff et $\mathrm{al}^{6}$ and McLaurin and Frame, ${ }^{12}$ the presence of an APC in a patient with a VP shunt implies shunt infection, even in the absence of clinical confirmation of infection. When APC is identified soon after shunt procedure, an infection may be responsible. The infection rate has been reported to be from 17 to $80 \%{ }^{9}, 13,14$ Gaskill and Marlin ${ }^{15}$ suggested infection to be a frequent predisposing factor after they found $16 \%$ to have an acute infection and $41.6 \%$ had a past history of CSF infection. Rainov et $\mathrm{a}^{9}$ found confirmed infection in $30 \%$ of their cases. In this study, we did not find any active infection, but one patient had a history of positive CSF infection in the past.

It has been proposed that smaller pseudocysts tend to be infected, and larger pseudocysts tend to be sterile, ${ }^{14,16}$ but Roitberg et $\mathrm{al}^{17}$ found no statistically significant connection between infection and pseudocyst size.

The most common bacterial species isolated include S. epidermidis or Staphylococcus aureus and Propionibacterium acnes. ${ }^{17}$ The late presentation of the APC may be related to (1) the remote shunt infection and previous shunt revision, (2) subclinical or sterile peritonitis leading to inflammatory changes and reduced absorptive power of peritoneum, and (3) a delayed immunologically mediated reaction to the shunt material. ${ }^{13}$ The CSF pseudocyst can either move freely within the peritoneal cavity or adhere to loops of small bowel, the serosal surface of solid organs, or the parietal peritoneum. Diagnosis of CSF pseudocyst can be established by ultrasound and $\mathrm{CT}$ scan examination of the abdomen and pelvis. The main features are an intraperitoneal fluid collection with or without internal septa and the distal tip of the shunt catheter within or close to the pseudocyst. USG is a fast and reliable method for the evaluation of the pseudocyst and other complications at the distal end of the VP shunt. ${ }^{4,6,18}$ CT scan, which provides precise information, is considered effective in the definitive diagnosis of APC when they are large and deform the normal architecture of the abdomen. ${ }^{19}$ It can help recognize other etiologies such as appendicitis, diverticulitis, abdominal abscess, or bowel obstruction. Differential diagnosis of a CSF APC includes lymphangioma, mesenteric cyst, pancreatic pseudocyst, duplication, and cystic teratoma. ${ }^{19}$ Plain radiographs are helpful to rule out other causes of acute abdomen and help determine the continuity of the catheter tube.

Management of CSF pseudocyst must be individualized. Obstruction of the distal catheter must be managed as an emergency as it can result in a significant increase in ICP as CSF is not absorbed across the serosa resulting in increased pressure within the cyst, reducing forward pressure gradient and optimal shunt function. ${ }^{1,20}$ The presence or absence of infection must be established before definitive treatment can be undertaken. There are various efficacious treatments for APC. When there is no infection, surgical excision of the cyst wall followed by relocating of the catheter in the peritoneal cavity is the preferred treatment. ${ }^{21,22}$ Percutaneous drainage of the cyst with or without surgical evacuation may be tried. ${ }^{23}$ Kim et al used excision and repositioning of the shunt tip with minimally invasive laparoscopic techniques. ${ }^{24}$ In some cases, the shunt converted to ventriculoatrial or ventriculopleural, ${ }^{14,25}$ leading to spontaneous resorption of the APC, and subsequent placement of the catheter back into the peritoneum without therapeutic drainage of the APC may lead to a functional VP shunt again. ${ }^{15}$ If an infection is found, the shunt is externalized and systemic antibacterial therapy administered followed by repositioning the of lower end into the abdomen later. ${ }^{6}$ Some authors objected repositioning of the peritoneal catheter in the abdomen in anticipation of recurrence. ${ }^{26}$ However, shunt replacement back into the abdomen has been feasible in most cases. ${ }^{14,25}$ Endoscopic third ventriculostomy may be achieved in selected cases after a shunt externalization. ${ }^{27}$

In our series, two patients underwent VP shunt operation for congenital hydrocephalus, one patient had a shunt for hydrocephalus following tuberculous meningitis, and one for hydrocephalous following repair of meningomyelocele. Formation of CSF pseudocyst in our cases was probably due to subclinical infection as active infection could not be documented in our patients. One patient had previously documented CSF culture positive, and two patients had distal 
shunt tube block and revision in this study. The cyst excision is vital for the shunt to function optimally and was done in our three cases. In three of our patients, the shunt was repositioned in the peritoneal cavity at the same exploration. One patient needed temporary exteriorization, followed by placement inside the peritoneum.

\section{Conclusion}

Abdominal pseudocysts are rare complications of VP shunt placement. Owing to the absence of suspiciousness, patients may develop a giant CSF APC. Post-VP shunt pseudocysts, whenever suspected, should be evaluated properly by imaging. Prompt management should be performed to prevent the deterioration of the patient.

\section{Conflicts of Interest}

None.

\section{Financial Disclosures}

None.

\section{Presentation at a Meeting}

None.

\section{References}

1 Grosfeld JL, Cooney DR, Smith J, Campbell RL. Intra-abdominal complications following ventriculoperitoneal shunt procedures. Pediatrics 1974;54(6):791-796

2 Bryant MS, Bremer AM, Tepas JJ III, Mollitt DL, Nquyen TQ Talbert JL. Abdominal complications of ventriculoperitoneal shunts. Case reports and review of the literature. Am Surg 1988;54(1):50-55

3 Sharma AK, Pandey AK, Diyora BD, Mamidanna R, Sayal PP. Abdominal CSF pseudocyst in a patient with ventriculo-peritoneal shunt. Indian J Surg 2004;66:360-363

4 Hahn YS, Engelhard H, McLone DG. Abdominal CSF pseudocyst. Clinical features and surgical management. Pediatr Neurosci 1985-1986;12(2):75-79

5 Narasimharao KL, Purohit A, Yadav K, Pathak IC. Recurrent abdominal pseudocyst after ventriculoperitoneal shunt. Aust Paediatr J 1984;20(1):73-74

6 Egelhoff J, Babcock DS, McLaurin R. Cerebrospinal fluid pseudocysts: sonographic appearance and clinical management. Pediatr Neurosci 1985-1986;12(2):80-86

7 Davidson RI, Lingley JF. Intraperitoneal pseudocyst: treatment by aspiration. Surg Neurol 1975;4(1):33-36

8 Ghritlaharey RK, Budhwani KS, Shrivastava DK, Jain AK, Gupta G, Kushwaha AS. CSF pseudocysts peritoneal cavity following V P Shunt surgery: Report of three cases in children and review of literature. J Indian Assoc Pediatr Surg 2006;11:41-43

9 Rainov N, Schobess A, Heidecke V, Burkert W. Abdominal CSF pseudocysts in patients with ventriculo-peritoneal shunts. Report of fourteen cases and review of the literature. Acta Neurochir (Wien) 1994;127(1-2):73-78
10 Parry SW, Schuhmacher JF, Llewellyn RC. Abdominal pseudocysts and ascites formation after ventriculoperitoneal shunt procedures. Report of four cases. J Neurosurg 1975;43(4):476-480

11 Hamid R, Baba AA, Bhat NA, Mufti G, Mir YA, Sajad W. Post ventriculoperitoneal shunt abdominal pseudocyst: challenges posed in management. Asian J Neurosurg 2017;12(1):13-16

12 McLaurin RL, Frame PT. Treatment of infections of cerebrospinal fluid shunts. Rev Infect Dis 1987;9(3):595-603

13 Yuh SJ, Vassilyadi M. Management of abdominal pseudocyst in shunt-dependent hydrocephalus. Surg Neurol Int 2012;3:146-149

14 Mobley LW III, Doran SE, Hellbusch LC. Abdominal pseudocyst: predisposing factors and treatment algorithm. Pediatr Neurosurg 2005;41(2):77-83

15 Gaskill SJ, Marlin AE. Pseudocysts of the abdomen associated with ventriculoperitoneal shunts: a report of twelve cases and a review of the literature. Pediatr Neurosci 1989;15(1):23-26, discussion 26-27

16 Goeser CD, McLeary MS, Young LW. Diagnostic imaging of ventriculoperitoneal shunt malfunctions and complications. Radiographics 1998;18(3):635-651

17 Roitberg BZ, Tomita T, McLone DG. Abdominal cerebrospinal fluid pseudocyst: a complication of ventriculoperitoneal shunt in children. Pediatr Neurosurg 1998;29(5):267-273

18 Agha FP, Amendola MA, Shirazi KK, Amendola BE, Chandler WF. Unusual abdominal complications of ventriculo-peritoneal shunts. Radiology 1983;146(2):323-326

19 Ouladsaiad M, Hokoumi H, Aballa N. A giant abdominal cerebrospinal fluid pseudocyst. Iran I Neurosurg 2017;3(3):109-114

20 Raghavendra BN, Epstein FJ, Subramanyam BR, Becker MH. Ultrasonographic evaluation of intraperitoneal CSF pseudocyst. Report of 3 cases. Childs Brain 1981;8(1):39-43

21 Kashyap S, Ghanchi H, Minasian T, Dong F, Miulli D. Abdominal pseudocyst as a complication of ventriculoperitoneal shunt placement: review of the literature and a proposed algorithm for treatment using 4 illustrative cases. Surg Neurol Int 2017;8:78

22 Fischer EG, Shillito J Jr. Large abdominal cysts: a complication of peritoneal shunts. Report of three cases. J Neurosurg 1969;31(4):441-444

23 Coley BD, Shiels WE II, Elton S, Murakami JW, Hogan MJ. Sonographically guided aspiration of cerebrospinal fluid pseudocysts in children and adolescents. AJR Am J Roentgenol 2004;183(5):1507-1510

24 Kim HB, Raghavendran K, Kleinhaus S. Management of an abdominal cerebrospinal fluid pseudocyst using laparoscopic techniques. Surg Laparosc Endosc 1995;5(2):151-154

25 Erşahin Y, Mutluer S, Tekeli G. Abdominal cerebrospinal fluid pseudocysts. Childs Nerv Syst 1996;12(12):755-758

26 Burchianti M, Cantini R. Peritoneal cerebrospinal fluid pseudocysts: a complication of ventriculoperitoneal shunts. Childs Nerv Syst 1988;4(5):286-290

27 de Oliveira RS, Barbosa A, Vicente YA, Machado HR. An alternative approach for management of abdominal cerebrospinal fluid pseudocysts in children. Childs Nerv Syst 2007;23(1):85-90 